\title{
Drug burden index, polypharmacy and patient health outcomes in cognitively intact older residents of aged care facilities in Malaysia
}

\section{Abstract}

Aim: To examine association of Drug Burden Index (DBI) and polypharmacy with patient health outcomes among cognitively intact older residents in aged care facilities.

Methods: A review of prescribed medications and related outcomes in a crosssectional sample of older adults, aged 60 years and above, recruited from 11 aged care facilities in Peninsular Malaysia. Groningen Frailty Indicator (GFI) for frailty, Older People's Quality of Life-35 (OPQoL) for quality of life, Drug Burden Index (DBI) to quantify patients' exposure to anticholinergic and sedative medicines and Hospital Anxiety and Depression Scale (HADS) for mental health of the residents.

Results: More than two-third of a sampled population received at least one anticholinergic or sedative medication and more than one-quarter of them were exposed to polypharmacy. Exposure to DBI-associated medications in 3 in every 4 frail participants and was significantly correlated with frailty $(r:+0.184$, $\mathrm{p}=0.023$ ). Frail population had significantly increased risk of polypharmacy (OR 6.07, 95\% Cl: 1.71-21.56, $\mathrm{p}=0.005)$. However, exposure to DBI-associated medications was not significantly associated with overall quality of life and activity of daily living measures.

Conclusion: Polypharmacy and anticholinergic and sedative burden were noticed in a substantial number of older adults in residential aged care and were associated with frailty. Investing in recruitment of pharmacists may benefit recognition of RACF quality of care as pharmacy services (including pharmacist) are virtually non-existent in Malaysian RACF.

Keywords: Aged care, drug burden, frailty, older people, polypharmacy 


\section{INTRODUCTION}

In 2015, the older people constituted 12\% (901 million) of the world population, and the total number of older persons is increasing by $3.26 \%$ annually. ${ }^{1}$ In Malaysia, the older people account for $6 \%$ of the population (2016), and estimated to rise to $14.5 \%$ by $2040 .{ }^{2}$ Because of age-related chronic diseases, the older people are likely to use regular long-term medications. Previous studies in the United States of America (USA) and Europe indicated a proportional increase in the number of medications used with age. ${ }^{3,4}$ The use of 5 or more medications concurrently is common in residential aged care facilities (RACF). ${ }^{5-8}$ Growing evidence suggests that polypharmacy in the older people is related to inappropriate medications. ${ }^{9}$ The proportion of potentially inappropriate medications related to polypharmacy was three times higher in RACF. ${ }^{10}$ Novaes et al., reported an "iatrogenic triad" of polypharmacy, inappropriate medications and drug-drug interactions in one in every three older people. ${ }^{11}$

The rising prevalence of medication inappropriateness in the older population is a major public health concern. For instance, the use of inappropriate medications is associated with poor physical functioning, that in the older people increases risks of falls, hip fracture and injuries. Nyborg et al., identified concomitant use of three or more psychotropic drugs, antihypertensives, and regular use of hypnotics as potentially inappropriate medications among Norwegian nursing home residents aged $\geq 70$ years whereas Bor et al., identified that potentially inappropriate medications such as pantoprazole, trimetazidine and vinpoctine were significant risk factors for falls among Hungarian older people in nursing homes. ${ }^{12,13}$ Juola et al., in Finland reported a stepwise association between use of multiple potentially harmful medications and poorer self-rated health, and poorer HRQoL. ${ }^{14}$ However, one study in Malaysia depicted the prevalence of potentially inappropriate medications among RACF but observed non-significant changes in HRQoL. ${ }^{15}$

Commonly prescribed medications for older adults in hospitals and community pharmacies are anticholinergics and sedatives; ${ }^{16,17}$ the number of anticholinergic prescriptions increased from 14,019 (20.6\%) in 1995 to 17,448 (23.6\%) in 2010. ${ }^{18-19}$ Anticholinergic side effects resulting from inhibition of 
muscarinic receptors include dry mouth, sleepiness, hallucinations, urinating problem, constipation and memory impairment. ${ }^{15} \mathrm{~A}$ high anticholinergic and sedative burden is associated with poor functional outcomes, ${ }^{20,21}$ and cognitive deficits. ${ }^{20}$ In Australia, anticholinergic and sedative burden were associated with poorer physical function such as slow walking speed, slow narrow walking speed and poorer score on the Instrumental Activities of Daily Living (IADLs) scale; the association was stronger with sedative medications. ${ }^{22}$

Various implicit and explicit tools have been developed to identify potentially inappropriate prescribing and medication. ${ }^{23-25}$ The Drug Burden Index (DBI) is used to estimate the exposure to anticholinergic and sedative medicines or burden. ${ }^{26}$ Associations between $\mathrm{DBI}$ and patient health outcomes are still very limited particularly in residential aged care settings in developing countries.

The aim of this study is to identify exposure to drug burden index (DBI) associated medications and polypharmacy in older residents through a detailed medication review performed by the pharmacists. In addition, the study aimed to examine whether the DBI and polypharmacy were associated with frailty in older adults living in residential care in Malaysia.

\section{METHODS}

\section{Study design, participants and setting}

A cross-sectional sample of older population aged $\geq 60$ years in residential aged care facilities (RACF) in mid-Western states of Peninsular Malaysia. In total, 11 RACF, run by not-for profit organisations, in Kuala Lumpur, Selangor, and Perak (Ipoh) were conveniently approached and selected. We assessed associations between DBI (i.e. exposure to anticholinergic and sedative medicines), exposure to polypharmacy and health outcomes (e.g. frailty) in RACF. Residents who met the criteria and had complete medical records were included in the study. Participants were able to take part if they had been permanent residents in the facility for six months or more, age $\geq 60$ years, had at least 1 long-term medical condition, received at least 1 long-term medication, able to articulate and provided verbal or written consent to participate. An interviewer-administered comprehensive assessment form (CAF) was used to collect data and the interviews took approximately 30 minutes. The data 
collection was completed in three months (July 2017 to September 2017). The form included information on demographic data (age, sex, race, marital status, education level, occupation history, number of children and siblings, physical activity level, and smoking, and alcohol status), QOL, mental health status, frailty status, and medication and medical history of the participants. In measuring covariates, patients' medical histories from the facilities were searched to determine if the participants had a clinical diagnosis of any longterm medical condition (including any cognitive related conditions, e.g. dementia). The data on co-morbid conditions were extracted from the medical records of the participants and documented as number of co-morbid conditions.

\section{Assessment of patient health outcomes}

Frailty was assessed using Groningen Frailty Indicator (GFI). The GFI, validated in institutional homes comprises fifteen dichotomous items with a score range from 0 (normal activity without restriction) to 15 (completely disabled). ${ }^{27,28}$ The GFI instrument has been used and validated in Malaysia. ${ }^{28}$ Participants with a score of $\geq 4$ were considered frail. ${ }^{27}$ The Katz ADL comprises six activities with each activity indicating independence or dependence. Total score range from 0 (full dependence) to 6 (full independence). ${ }^{29}$ QoL was measured using the OPQOL questionnaire. ${ }^{30} \mathrm{OPQOL}$ comprises 35 items in 8 domains: life overall, health, social relationship, independence, home, psychological, financial and leisure. Each item had five-point Likert scales (1-5, higher scores indicating better QoL). Total OPQOL score range from 35 (worst possible) to 175 (best possible). ${ }^{30,31} \mathrm{OPQOL}$ is a multidimensional, population surveillance instrument, specifically designed for use with older populations. ${ }^{30,31}$ Our reliability analysis found this instrument as reliable (Cronbach alpha: 0.70). Mental health status as a covariate was evaluated using the HADS. ${ }^{11,32}$ HADS is a useful and valid instrument to screen anxiety and depression symptoms in older adults. ${ }^{32}$ HADS consists of 14 items with each item rated on a four-point (0-3) Likert scale, providing a score range from 0 to 42 , with a higher score indicating worse mental health status. ${ }^{33}$ 


\section{Drug burden index and polypharmacy}

Exposure to a $\mathrm{DBI}$-associated medication was defined as exposure to an affected medication during the three months' period. DBI refers to anticholinergic and/or sedative medicines exposure. It was calculated with a validated formula of Drug Burden Index $=D /(D+\delta),{ }^{26}$ where $D$ is the daily dose taken by the individual (derived from medical records), and $\delta$ is the minimum efficacious dose which was approved and registered by the Ministry of Health Malaysia (Formulari Ubat KKM (FUKKM, March 2016). The Malaysian product information and Monthly Index of Medical Specialities (MIMS Malaysia, paperback 2017) were used to identify medications with clinically significant anticholinergic and/or sedative effects. Complementary medications, health supplements and medications prescribed on a PRN basis (i.e. when required) were excluded. ${ }^{34}$ For this study, polypharmacy is defined when participants are on $\geq 5$ concurrent medications at a single time. Patients' medical records obtained from each participating RACF were searched to assess medicines use. The data collected included the name, dose, and dosing instructions of all the medications used three months prior to the start date of the study at each facility.

\section{Statistical analysis}

The data analysis was performed using Statistical Package for Social Sciences (SPSS version 24) $\AA$ with a significance level of 0.05 . The collected data are presented as frequencies, percentages, means and standard deviations. Chisquare test was used to compare patient health outcomes and medicationrelated variables (e.g. frailty and polypharmacy; frailty and drug burden index). For assessing associations, Spearman correlation was used such as between drug burden index, medication appropriateness and patient health outcomes. The GFI, OPQOL, HADS depression and anxiety, and KATZ ADL scales were converted to binary variables. The KATZ ADL scores of 0 to 6 were reverse coded and categorised as dependence (score $>0$ ) and independence (score $=$ 0 ). Binary variables for total OPQOL score (35 to 175) were obtained using median split method. ${ }^{35}$ A HADS score of 7 was used to categorise cases and non-cases of depression and anxiety. ${ }^{36}$ It has been found that at a cut-off score 
of $8+(>7)$ for both subscales provide sensitivities and specificities of approximately $0.80 .^{32}$

Univariate and multivariate logistic regression models were used to examine associations between (1) polypharmacy and GFI, OPQOL, HADS and KATZ ADL measures (binary variables) and (2) having a $\mathrm{DBI}>0$ and $\mathrm{GFI}, \mathrm{OPQOL}$, HADS and KATZ ADL measures (binary variables). The potential confounders were identified based on their association with main variables and on the basis of a priori knowledge. 26,37 We determined variables necessary to control for confounding and that includes age, sex, marital status, co-morbidity, patient health outcomes, and medication-related variables.

\section{RESULTS}

\section{Socio-demographic characteristics of the participants}

The socio-demographic characteristics of study participants are presented in Table 1. During the data collection period, about 200 residents of aged care homes were screened. Of these, 151 met the inclusion criteria and participated in this study. A similar number of both genders (77 males, 51\%) participated in this study. The mean age was $74.50 \pm 8.40$ and most participants were of Chinese ethnicity $(n=148,98 \%)$. Half of the participants were single ( $n=80$, $53 \%)$ and had not received any formal education ( $n=77,51 \%)$. The average number of co-morbid conditions was $2.31 \pm 1.19$. Figure 1 presents the preexisting medication conditions at the time of study. Cardiovascular related conditions were the most common medical conditions associated with study participants. Only $6 \%$ of the participants had psychiatric conditions (e.g. schizophrenia or depression).

\section{Patient health outcomes}

Majority of the participants had some degree of dependence (78.8\%) and were frail $(68.2 \%)$, as shown in Table 2. The average quality of life score (total OPQOL score) was $109.9 \pm 8.0$ with the leisure domain recording the highest score $(18.73 \pm 1.3)$ and the financial domain with the lowest score $(12.09 \pm 1.3)$. 


\section{Medicines use of the participants}

The average number of medications per participant was $3.54 \pm 1.96$ (Table 2). There were 41 participants $(27.15 \%)$ who were taking more than 5 medications (polypharmacy). More than two-thirds (74.2\%) of the study population received at least one anticholinergic or sedative medication included in the DBI. CVS medications were the most commonly used medications having anticholinergic properties.

The exposure to polypharmacy occurred in almost $35 \%$ of the frail population, which was significantly higher than non-frail participants $(p=0.001)$. No significant differences were observed for other groups (Table 3).

\section{Drug Burden Index and patient health outcomes}

Exposure to $\mathrm{DBI}$-associated medications in 3 in every 4 frail participants. The DBI was significantly and positively correlated with GFI scores $(r:+0.184, p=$ 0.023). Being exposed to DBI-associated medications was not significantly associated with total OPQOL scores as compared to not being exposed to a DBI. Among all OPQOL domains, only one (home) was significantly correlated with $\mathrm{DBI}(r:+0.189, p=0.020)$, respectively.

In a multivariate logistic regression, frail participants had significantly increased odds of receiving 5 or more medications (OR $6.07,95 \% \mathrm{Cl}$ : $1.71-21.56$ ), as shown in Table 4. Frail participants and those with poor QOL had an increased risk of receiving $\mathrm{DBI}$-associated medications, but their associations were not statistically significant.

\section{DISCUSSION}

The present study evaluates association of drug burden index and polypharmacy with patient health outcomes in older adults in RACF. Around two-third of participants were frail as measured by GFI scores. Drug burden as measured by DBI has an average score of $0.79 \pm 0.63$ and showed a correlation with frailty. Occurrence of polypharmacy was a feature of approximately a quarter of the participants. In this study, frailty was associated with higher exposure to polypharmacy ( $\geq 5$ medications) in a population of older adults ( $\geq$ 60 years) in residential aged care in Malaysia. 
There was a relatively high proportion of anticholinergic and sedative burden among residents $(74.17 \%)$ and was significantly correlated with frailty as indicated by GFI. Many studies that have reported an association between drug burden and physical function in the older population have not included aged care home residents. ${ }^{22,26,38,39}$ A five-year longitudinal study in the United States depicted that high DBI scores were associated with low functional outcomes measured using short physical performance battery, gait speed and grip strength; ${ }^{26,38}$ a similar association was reported in other countries. ${ }^{22,39}$ The predictive relationship between drug burden and frailty in this study was not strong possibly due to coefficient values and wide confidence intervals despite significant $p$-values; self-reported measures in this study may have also contributed to such results.

It is possible that more than half of the participants in this study are frail owing to their poor health status characterised by (mostly severe) disability, high degree of functional dependence, and medication inappropriateness, all of which are prevalent in residents of aged care facilities. ${ }^{40}$ The older people residing in aged care facilities portray vulnerability within the ageing segment and their health needs are complex owing to multiple-comorbidities and agedcare changes in their pharmacokinetic and pharmacodynamics characteristics. ${ }^{41,42}$ Frailty is also associated with deterioration in physical function and increased risk of falls, injury, fracture, hospital admission and mortality. ${ }^{43-48}$ Although use of anticholinergic and sedative medications further impairs physical function, ${ }^{16}$ there were no significant differences between drug burden and the frail and non-frail groups possibly due to the sample size and self-report measures of frailty.

Older people are often prescribed with inappropriate medications. ${ }^{14,43,44}$ Although exposure to anticholinergic and sedative medications occurred in over three-quarter of a population of older adults in residential aged care, its association with lower or poorer quality of life was not statistically significant. In contrast, Harrison et al., (2018) found that exposure to DBI-associated medications was associated with lower QOL according to the EuroQol-5 Dimensions Questionnaire. ${ }^{45}$ Medication inappropriateness identified by the Red-Yellow-Green List was also associated with reduced quality of life 
measured using the EuroQol-5D (EQ-5D) and low functional status measured by the New Mobility Score. ${ }^{46}$ Inappropriate medications potentially worsen health via noxious effects that may trigger a harmful prescribing cascade. ${ }^{11}$

Also, the risk of receiving five or more medications was six times higher for frail as compared to non-frail participants. A review showed a link between polypharmacy and poor physical functioning in which there was a significant difference in the polypharmacy and non-polypharmacy groups in terms of inappropriate medication use measured using STOPP. ${ }^{47}$ A recent study conducted among community-dwelling older persons in Malaysia reported a high prevalence of polypharmacy among the older people and the main associated risk factor was inappropriate medications. ${ }^{9}$ Other studies also reinforced medication inappropriateness as a risk factor of polypharmacy. ${ }^{13,48}$ Around one in three older persons who take at least five medications is bound to experience an adverse drug reaction, ${ }^{49}$ that lead to hospital presentations; 50 interestingly adverse drug reactions in at least one quarter of these older people are preventable by avoiding inappropriate medications. ${ }^{50}$ Individuals taking $\geq 5$ medications have higher risks of drug-drug interactions and drug-disease interactions compared to those taking fewer medications.

\section{Potential role of pharmacists in aged care facilities}

The current healthcare system in Malaysia has mandated laws to govern aged care facilities in Malaysia; Act 506 of the Care Centres Act 1993, ${ }^{51}$ and Act $586,{ }^{52}$ of the Private Healthcare Facilities and Services Act 1998 govern the current welfare of older people in aged care facilities. Act 506 is implemented for the private sector, specifically the civil society and governs 244 care centres, old folks' homes, shelters, etc. ${ }^{51}$ while Act 586 is implemented for the businessoperated private sector and governs 21 nursing homes, 244 care centres, dualkey residences, retirement villages, etc. ${ }^{52}$ More recently, the Private Aged Healthcare Facilities and Services Act 2017 was gazetted in 2018 under Act 802 but has not been mandated; 53 this act dictates the approval and licensing requirements to operate private aged care facilities and services. ${ }^{53}$ The advent of these acts is expected to further strengthen the regulation of aged care facilities in Malaysia. However, the current acts do not mandate the presence 
of pharmacists in RACF, and it might be worthwhile exploring their potential in improving patient safety of the aged care population.

Although the Pharmaceutical Services Division of the Ministry of Health Malaysia provides pharmaceutical care services such as Home Medication Reviews (HMR) and strategies to improve the Quality Use of Medicines to older patients residing in RACF and even their own homes, it is worth considering a mandatory approach for pharmacists to steer medication-optimisation strategies in RACF. Given that RACF in Malaysia are not deemed as healthcare facilities, residents are required to seek medical treatment at their own capacity in private or governmental healthcare facilities such as private clinics and hospitals, or government-subsidised health clinics and hospitals. This scenario may give rise to a long list of medications (and polypharmacy), in addition to duplication of medications. Although there are strategies in place to improve the welfare quality of life of residents in RACF in Malaysia, these services may be underutilised. It would be feasible to ensure community and hospital pharmacists conduct medication reviews on a part-time basis in RACF, as this has shown to improve the quality of medication use. ${ }^{54}$ Since the HMR service has been established by the Ministry of Health, this strategy could be expanded to incorporate reviews for residents in RACF by implementing a schedulebased approach for government pharmacists to visit RACF on a weekly basis to provide medication review services. Pharmacists can take turns to perform these services on a rotation basis during office hours as a pilot programme so that financial reimbursements may not hinder the implementation of this service. Furthermore, appropriate training under the Continuous Professional Development scheme should be provided to pharmacists who will be providing the medication reviews to ensure optimal provision of care for the residents. It is recommended that the reviews be aided by tools such as medication review algorithms and medication-appropriateness quantifying tools. ${ }^{55,56}$ Results from the pilot study will aid in further strengthening of this service. Such initiatives by pharmacists may ultimately improve the quality of life and reduce the incidence of frailty among the older people.

The strength of this study is grounded on its high reliability for all assessments. Despite robust methods, there are several limitations to the research. There 
was a possibility of temporal and indication bias (decline in functioning may have preceded use of $\mathrm{DBI}$-associated drugs). Although known cases were excluded, the presence of unknown cognitive issues in the study population may have influenced the study results. The use of an interviewer-administered questionnaire may have caused significant bias in the study outcomes. Participants were predominantly Chinese; therefore, the results cannot represent the entire older population in Malaysia. Recall bias may have been induced in self-reported measures. Selection bias may have been introduced into this study due to the study sites that represent aged care facilities in the urban area. The inclusion of different homes may have led to variation of results as prescribing patterns differ between clinicians. Although we observed a significant correlation between home domain of OPQOL and DBI, items in this domain may not be sensitive to people living in residential aged care homes.

In conclusion, the number of participants exposed to DBI-associated medications were more than double the number of those exposed to polypharmacy among older adults living in residential aged care facilities in Malaysia. However, exposure to DBI-associated medications was not significantly associated with overall quality of life measure. The anticholinergic and sedative burden, and polypharmacy were significantly associated with frailty. Prescribers should exercise caution when prescribing and medications must be reviewed periodically. Future longitudinal studies can evaluate impact of interventions such as periodic medication reviews on physical and cognitive function, and can determine cost-benefit relationships.

Conflict of interests' statement: The authors declare that they have no conflict of interests.

\section{ETHICS STATEMENT}

The ethics approval was obtained from the International Medical University Joint-Committee on Research and Ethics (Project ID: BPI-1-14-(09)2017). Also, permission from individual RACF management was obtained before data collection. The collected data was stored in a password-protected file accessible only to the researchers. 


\section{References}

1. United Nations-Department of Economic and Social Affairs. The World Population Prospects: 2015 Revision. Available from < http://www.un.org/en/development/desa/publications/world-population-prospects2015-revision.html > Accessed 15 June 2017

2. Department of Statistics Malaysia Official Portal. Population Projection (Revised), Malaysia, 2010-2040. Available from < https://www.dosm.gov.my/v1/index.php?r=column/cthemeByCat\&cat=118\&bul i $\mathrm{d}=Y 3 \mathrm{kwU2tSNVFDOWp1YmtZYnhUeVBEdz09 \& menu} \mathrm{id=LOpheU43NWJwRW}$ VSZkIWdzQ4TIhUUT09> Accessed 18 June 2017

3. Kaufman DW, Kelly JP, Rosenberg L, Anderson TE, Mitchell AA. Recent patterns of medication use in the ambulatory adult population of the United States: the Slone survey. JAMA. 2002;287(3):337-44.

4. Barat I, Andreasen F, Damsgaard EM. The consumption of drugs by 75 -year-old individuals living in their own homes. European Journal of Clinical Pharmacology 2000;56(6-7):501-9.

5. Herr M, Grondin H, Sanchez S. et al. Polypharmacy and potentially inappropriate medications: a cross-sectional analysis among 451 nursing homes in France. European Journal of Clinical Pharmacology 2017;73(5):601-8.

6. Barnett K, McCowan C, Evans JMM, Gillespie ND, Davey PG, Fahey T. Prevalence and outcomes of use of potentially inappropriate medicines in older people: cohort study stratified by residence in nursing home or in the community. BMJ Quality Safety 2011;20(3):275-81.

7. Halvorsen $\mathrm{KH}$, Granas AG, Engeland A, Ruths S. Prescribing quality for older people in Norwegian nursing homes and home nursing services using multidose dispensed drugs. Pharmacoepidemiology \& Drug Safety 2012;21(9):929-36.

8. Haasum $\mathrm{Y}$, Fastbom J, Johnell $\mathrm{K}$. Institutionalization as a risk factor for inappropriate drug use in the elderly: A Swedish nationwide register-based study. Annals of Pharmacotherapy 2012;46(3):339-46.

9. Lim LM, McStea M, Chung WW, et al. Prevalence, risk factors and health outcomes associated with polypharmacy among urban community-dwelling older adults in multi-ethnic Malaysia. PloS One 2017;12(3):e0173466.

10. Bao Y, Shao H, Bishop TF, Schackman BR, Bruce ML. Inappropriate medication in a national sample of US elderly patients receiving home health care. Journal of General Internal Medicine 2012;27(3):304-10.

11. Novaes PH, da Cruz DT, Lucchetti ALG, Leite ICG, Lucchetti G. The "iatrogenic triad": polypharmacy, drug-drug interactions, and potentially inappropriate medications in older adults. International Journal of Clinical Pharmacy 2017 Apr 28;

12. Bor $A$, Matuz M, Csatordai M, et al. Medication use and risk of falls among nursing home residents: a retrospective cohort study. International Journal of Clinical Pharmacy 2017;39(2):408-15.

13. Nyborg G, Brekke M, Straand J, Gjelstad S, Romoren M. Potentially inappropriate medication use in nursing homes: an observational study using the NORGEP-NH criteria. BMC Geratrics 2017;17:220.

14. Juola A-L, Pylkkanen S, Kautiainen $\mathrm{H}$, et al. Burden of Potentially Harmful Medications and the Association with Quality of Life and Mortality Among 
Institutionalized Older People. Journal of American Medical Directors' Association 2016;17(3): 276.e9-14. [14]

15. Al Aqqad SMH, Chen LL, Shafie AA, Hassali MA, Tangiisuran B. The use of potentially inappropriate medications and changes in quality of life among older nursing home residents. Clinical Interventions in Aging 2014;9:201-7.

16. Nishtala PS, Narayan SW, Wang T, Hilmer SN. Associations of drug burden index with falls, general practitioner visits, and mortality in older people. Pharmacoepidemiology \& Drug Safety 2014;23(7):753-8.

17. Chew ML, Mulsant BH, Pollock BG, et al. Anticholinergic activity of 107 medications commonly used by older adults. Journal of the American Geriatrics Society 2008;56(7):1333-41.

18. Rothberg MB, Herzig SJ, Pekow PS, Avrunin J, Lagu T, Lindenauer PK. Association between sedating medications and delirium in older inpatients. Journal of the American Geriatrics Society 2013;61(6):923-30.

19. Sumukadas D, Mcmurdo M, Mangoni A, Guthrie B. Anticholinergic burden of medications in older people: Prescription trends over 15 years. European Geriatric Medicine 2012;3:S22.

20. Cao Y-J, Mager DE, Simonsick EM, et al. Physical and cognitive performance and burden of anticholinergics, sedatives, and ACE inhibitors in older women. Clinical Pharmacology \& Therapeutics 2008;83(3):422-9.

21. Hilmer SN, Mager DE, Simonsick EM, Ling SM, Windham BG, Harris TB, et al. Drug burden index score and functional decline in older people. American Journal of Medicine 2009;122(12):1142-1149-2.

22. Gnjidic D, Cumming RG, Le Couteur DG, Handelsman DJ, Naganathan V, Abernethy DR, et al. Drug Burden Index and physical function in older Australian men. British Journal of Clinical Pharmacology 2009;68(1):97-105.

23. Hanlon JT, Schmader KE. The Medication Appropriateness Index at 20: Where it Started, Where it has been and Where it May be Going. Drugs and Aging. 2013;30(11):893-900.

24. Fick DM, Cooper JW, Wade WE, Waller JL, Maclean JR, Beers MH. Updating the Beers criteria for potentially inappropriate medication use in older adults: results of a US consensus panel of experts. Archives of Internal Medicine 2003;163(22):2716-2724.

25. O'Mahony D, O'Sullivan D, Byrne S, O'Connor MN, Ryan C, Gallagher P. STOPP/START criteria for potentially inappropriate prescribing in older people: version 2. Age and Ageing 2015;44(2):213-218.

26. Hilmer SN, Mager DE, Simonsick EM, et al. A drug burden index to define the functional burden of medications in older people. Archives of Internal Medicine 2007;167(8):781-787.

27. Steverink N, Slaets JPJ, Schuurmans H, Lis M van. Measuring frailty: Developing and testing the GFI (Groningen frailty indicator). The Gerontologist 2001;41:236237.

28. Hasan SS, Kow CS, Thiruchelvam K, et al. An evaluation of the central nervous system medication use and frailty among residents of aged care homes in Malaysia. Neuroepidemiology 2017;49(1-2):82-90.

29. Katz S. Assessing self-maintenance: activities of daily living, mobility, and instrumental activities of daily living. Journal of the American Geriatrics Society 1983;31(12):721-7. 
30. Bowling A. The Psychometric Properties of the Older People's Quality of Life Questionnaire, Compared with the CASP-19 and the WHOQOL-OLD. Current Gerontology and Geriatrics Research 2009(1687-7063):e298950.

31. Bowling A, Stenner $P$. Which measure of quality of life performs best in older age? A comparison of the OPQOL, CASP-19 and WHOQOL-OLD. Journal of Epidemiology and Community Health 2011;65(3):273-80.

32. Bjelland I, Dahl AA, Haug TT, Neckelmann D. The validity of the Hospital Anxiety and Depression Scale. An updated literature review. Journal of Psychosomatic Research 2002;52(2):69-77.

33. Zigmond AS, Snaith RP. The Hospital Anxiety and Depression Scale. Acta Psychiatrica Scandinavica 1983;67:361-370.

34. Hasan SS, Liew ASC, Chong DWK, Thiruchelvam K, Babar ZUD. Associations between Drug Burden Index, medication appropriateness and patient-reported outcomes in the community pharmacy setting in Malaysia. Drugs \& Therapy Perspectives (2018). https://doi.org/10.1007/s40267-018-0521-3

35. Hasan SS, Thiruchelvam K, Ahmed SI, et al. Relation between mental healthrelated variables and glycemic control in Malaysian women with type 2 diabetes mellitus (T2DM). International Journal of Diabetes in Developing Countries 2014;35(3):211-218.

36. Snaith RP. The Hospital Anxiety and Depression Scale. Health and Quality of Life Outcomes 2003; 1: 29.

37. Harrison SL, O'Donnell LK, Bradley CE, et al. Associations between the Drug Burden Index, Potentially Inappropriate Medications and Quality of Life in residential Aged Care. Drugs and Aging 2018;35:83-91

38. Hilmer SN, Mager DE, Simonsick EM, et al. Drug burden index score and functional decline in older people. American Journal of Medicine 2009;122(12):1142-1149-2.

39. Wilson NM, Hilmer SN, March LM, et al. Associations between drug burden index and falls in older people in residential aged care. Journal of the American Geriatrics Society 2011;59(5):875-80.

40. Fougère $B$, Kelaiditi $E$, Hoogendijk $E O$, et al. Frailty Index and Quality of Life in Nursing Home Residents: Results From INCUR Study. The Journals of Gerontology. Series A, Biological Sciences and Medical Sciences 2016; 71(3): 420-424.

41. Fried LP, Tangen CM, Walston J, et al. Frailty in older adults: evidence for a phenotype. The Journals of Gerontology. Series A, Biological Sciences and Medical Sciences 2001;56(3), M146-156.

42. Walston J, Hadley EC, Ferrucci L, et al. Research agenda for frailty in older adults: toward a better understanding of physiology and etiology: summary from the American Geriatrics Society/National Institute on Aging Research Conference on Frailty in Older Adults. Journal of the American Geriatrics Society 2006;54(6):9911001.

43. Chen LL, Tangiisuran B, Shafie AA, Hassali MAA. Evaluation of potentially inappropriate medications among older residents of Malaysian nursing homes. International Journal of Clinical Pharmacy 2012;34(4):596-603.

44. Ubeda A, Ferrándiz L, Maicas N, Gomez C, Bonet M, Peris JE. Potentially inappropriate prescribing in institutionalised older patients in Spain: the STOPP- 
START criteria compared with the Beers criteria. Pharmacy Practice 2012;10(2):83-91.

45. Harrison SL, O'Donnell LK, Bradley CE, et al. Associations between the Drug Burden Index, Potentially Inappropriate Medications and Quality of Life in residential Aged Care. Drugs and Aging 2018;35:83-91

46. Jensen LD, Andersen O, Hallin M, Petersen J. Potentially inappropriate medication related to weakness in older acute medical patients. International Journal of Clinical Pharmacy 2014;36(3):570-580.

47. Hammond T, Wilson A. Polypharmacy and falls in the elderly: a literature review. Nursing and Midwifery Studies 2013;2(2):171-175.

48. Rodrigues MCS, Oliveira $C$ de. Polypharmacy and falls in the elderly: a literature review. Revista Latino-americano de Enfermagem 2016 ;24:e2800.

49. Hanlon JT, Schmader KE, Koronkowski MJ, et al. Adverse drug events in high risk older outpatients. Journal of the American Geriatrics Society 1997; 45(8):945948.

50. Beijer HJ, de Blaey CJ. Hospitalisations caused by adverse drug reactions (ADR): a meta-analysis of observational studies. Pharmacy World \& Science 2002;24(2):46-54.

51. Laws of Malaysia Act 586: Private Healthcare Facilities and Services Act 1998. Available from <http://rr.mpc.gov.my/data/license-legal-523a4175de661.pdf > Accessed 16 November 2018

52. http://demo.rehdaselangor.com/wp-content/uploads/Act-586.pdf

53. Laws of Malaysia. Act A1485. Available from $<$ http://www.federalgazette.agc.gov.my/outputaktap/20150604 A1485 BI Act\% 20A1485.pdf> Accessed 16 November 2018

54. Thiruchelvam K, Hasan SS, Wong PS, Kairuz T. Residential Aged Care Medication Review to Improve the Quality of Medication Use: A Systematic Review. Journal of the American Medical Directors Association 2017;18(1):87.e187.e14.

55. Hanlon JT, Schmader KE, Samsa GP, et al. A method for assessing drug therapy appropriateness. Journal of Clinical Epidemiology 1992;45(10): 1045-1051.

56. Thiruchelvam K, Wong PS, Kairuz T, Babar ZUD, Hasan SS. Consolidated Medication Review Algorithm to Improve Medications Use in Older Adults: Components, Scoring Scheme, and Implementation. Journal of the American Medical Directors Association 2018; S1525-8610(18)30131-2 
Table 1: Socio-demographic characteristics of study participants $(n=151)$

\begin{tabular}{|c|c|c|}
\hline Variables & $\mathrm{n}$ & $\%$ \\
\hline \multicolumn{3}{|l|}{ Gender } \\
\hline Male & 77 & 50.99 \\
\hline Female & 74 & 49.01 \\
\hline Age (Mean \pm SD) & \multicolumn{2}{|c|}{$74.50 \pm 8.40$} \\
\hline \multicolumn{3}{|l|}{ Age Group } \\
\hline $60-70$ & 49 & 32.45 \\
\hline $71-80$ & 66 & 43.71 \\
\hline $81-90$ & 30 & 19.87 \\
\hline$>90$ & 6 & 3.97 \\
\hline \multicolumn{3}{|l|}{ Ethnicity } \\
\hline Chinese & 148 & 98.01 \\
\hline Indian & 3 & 1.99 \\
\hline \multicolumn{3}{|l|}{ Marital Status } \\
\hline Single & 80 & 39.85 \\
\hline Married & 50 & 37.59 \\
\hline Widowed & 3 & 2.26 \\
\hline \multicolumn{3}{|l|}{ Education level } \\
\hline None & 77 & 53.47 \\
\hline Primary & 59 & 40.97 \\
\hline Secondary & 6 & 4.17 \\
\hline Tertiary & 2 & 1.39 \\
\hline Number of co-morbid conditions, (Mean \pm SD) & \multicolumn{2}{|c|}{$2.31 \pm 1.19$} \\
\hline
\end{tabular}


Table 2: Patient-reported outcomes $(n=151)$

\begin{tabular}{|c|c|c|c|}
\hline Variables & Value & Maximum & Minimum \\
\hline Katz ADL, mean (SD) & $1.00(2.10)$ & 6 & 0 \\
\hline Independence (score = 0), n (\%) & $32(21.2)$ & - & - \\
\hline Dependence (score $>0), \mathrm{n}(\%)$ & $119(78.80)$ & - & - \\
\hline GFI Score, mean (SD) & $4.60(2.70)$ & 13 & 0 \\
\hline Non-Frail (score < 4), n (\%) & $48(31.80)$ & - & - \\
\hline Frail (score $\geq 4), n(\%)$ & $103(68.20)$ & - & - \\
\hline HADS Score, mean (SD) & $8.60(5.20)$ & 45 & 1 \\
\hline Anxiety Score, mean (SD) & $4.00(2.80)$ & 11 & 0 \\
\hline No Anxiety (score 0-7), n (\%) & $132(87.40)$ & - & - \\
\hline Anxiety case (score > 7), n (\%) & $19(12.60)$ & - & - \\
\hline Depression Score, mean (SD) & $4.90(3.80)$ & 36 & 0 \\
\hline No depression (score 0-7), n (\%) & $126(83.4)$ & - & - \\
\hline Depression case (score > 7), n (\%) & $24(15.90)$ & - & - \\
\hline OPQoL-35, mean (SD) & $109.90(8.0)$ & 142 & 91 \\
\hline Good OPQOL (111-175), n (\%) & $72(47.70)$ & - & - \\
\hline Poor OPQOL (35-110), n (\%) & $79(52.30)$ & - & - \\
\hline Overall Life, mean (SD) & $13.10(1.50)$ & 18 & 9 \\
\hline Health, mean (SD) & $12.30(1.20)$ & 17 & 8 \\
\hline Social, mean (SD) & $15.40(1.20)$ & 18 & 9 \\
\hline Independence, mean (SD) & $12.60(1.40)$ & 15 & 9 \\
\hline Home, mean (SD) & $15.20(2.70)$ & 20 & 9 \\
\hline Psychological, mean (SD) & $13.80(2.40)$ & 20 & 8 \\
\hline Financial, mean (SD) & $12.10(1.30)$ & 16 & 7 \\
\hline Leisure, mean (SD) & $18.70(1.30)$ & 50 & 12 \\
\hline \multicolumn{4}{|l|}{ Medicine use \& DBI } \\
\hline Total number of medications, mean (SD) & $3.54(1.96)$ & 9 & 1 \\
\hline Polypharmacy, n (\%) & $41(27.15)$ & & \\
\hline $\mathrm{DBI}>0(\mathrm{n}, \%)$ & $112(74.17)$ & & \\
\hline DBI, mean (SD) & $0.79(0.63)$ & 2 & 0 \\
\hline DBI, median (IQR) & $0.67(0.00-1.33)$ & & \\
\hline
\end{tabular}

Note: KATZ ADL- Katz Index of Independence in Activities Daily Living; HADS- Hospital Anxiety and Depression Scale; OPQoL-35- Older People's Quality of Life-35; SD - Standard Deviation; IQR - Inter Quartile Range 
Table 3: Frequencies and percentages of polypharmacy and DBI by patient-reported outcomes

\begin{tabular}{|c|c|c|c|c|}
\hline \multirow[t]{2}{*}{ Health Outcomes } & \multicolumn{2}{|c|}{ Polypharmacy } & \multicolumn{2}{|c|}{ Drug Burden Index (DBI) } \\
\hline & $\begin{array}{c}\text { No } \\
n(\%)\end{array}$ & $\begin{array}{c}\text { Yes } \\
\mathrm{n}(\%)\end{array}$ & $\begin{array}{c}\mathrm{DBI}=0 \\
\mathrm{n}(\%)\end{array}$ & $\begin{array}{c}\mathrm{DBI}>0 \\
\mathrm{n}(\%)\end{array}$ \\
\hline \multicolumn{5}{|l|}{ GFI } \\
\hline Non Frail $(<4)$ & $43(28.48)^{*}$ & $5(3.31)$ & $16(10.59)$ & $32(21.19)$ \\
\hline Frail $(\geq 4)$ & $67(44.37)$ & $36(23.84)$ & $25(16.56)$ & $78(51.66)$ \\
\hline \multicolumn{5}{|l|}{ OPQOL-35 } \\
\hline Poor (35-110) & $54(35.76)$ & $18(11.92)$ & $18(11.92)$ & $54(35.76)$ \\
\hline Good (111-175) & $56(37.10)$ & $23(15.23)$ & $23(15.23)$ & $56(37.09)$ \\
\hline Overall Life, mean (SD) & $13.16(1.41)$ & $13.05(1.64)$ & $13.20(13.32)$ & $13.11(1.52)$ \\
\hline Health, mean (SD) & $12.33(1.17)$ & $12.24(1.37)$ & $12.48(1.28)$ & $12.24(1.21)$ \\
\hline Social, mean (SD) & $15.34(1.04)$ & $15.49(1.52)$ & $15.28(1.17)$ & $15.41(1.19)$ \\
\hline Independence, mean (SD) & $12.60(1.38)$ & $12.56(1.55)$ & $12.55(1.45)$ & $12.60(1.42)$ \\
\hline Home, mean (SD) & $15.11(2.73)$ & $15.37(2.59)$ & $14.40(2.29)$ & $15.46(2.77)$ \\
\hline Psychological, mean (SD) & $13.94(2.47)$ & $13.32(2.15)$ & $13.68(2.79)$ & $13.80(2.25)$ \\
\hline Financial, mean (SD) & $12.07(1.28)$ & $12.12(1.50)$ & $11.83(1.13)$ & $12.18(1.40)$ \\
\hline Leisure, mean (SD) & $18.83(3.47)$ & $18.46(1.79)$ & $19.25(5.28)$ & $18.54(1.77)$ \\
\hline Total OPQoL, mean (SD) & $110.07(7.96)$ & $109.34(8.31)$ & $109.33(9.23)$ & $110.06(7.60)$ \\
\hline \multicolumn{5}{|l|}{ HADS - Depression } \\
\hline No $(\leq 7)$ & $93(61.59)$ & $33(21.85)$ & $32(21.19)$ & $94(62.25)$ \\
\hline Yes $(>7)$ & $17(11.26)$ & $7(4.64)$ & $9(5.96)$ & $15(9.93)$ \\
\hline \multicolumn{5}{|l|}{ HADS - Anxiety } \\
\hline No $(\leq 7)$ & $97(64.24)$ & $35(23.18)$ & $35(23.18)$ & $97(64.24)$ \\
\hline Yes (> 7) & $13(8.61)$ & $6(3.97)$ & $6(3.97)$ & $13(8.61)$ \\
\hline \multicolumn{5}{|l|}{ KATZ ADL } \\
\hline Independence (= 0) & $21(13.91)$ & $11(26.80)$ & $10(6.62)$ & $22(14.57)$ \\
\hline Dependence $(>0)$ & 89 (58.94) & $30(19.87)$ & $31(20.53)$ & $88(58.28)$ \\
\hline
\end{tabular}

Note: ${ }^{*}=p<0.05 ;$ Chi-Sq was used to obtain p-value; HADS = Hospital Anxiety and Depression Scale; KATZ ADL = Katz Index of Independence in Activities of Daily Living; OPQOL = Older People's Quality of Life; GFI = Groningen Frailty Indicator 
Table 4: Unadjusted and adjusted Odds Ratios (95\% Cl) of reporting exposure to polypharmacy and DBI, by patient-reported outcomes

\begin{tabular}{|c|c|c|}
\hline Health outcomes & $\begin{array}{c}\text { Polypharmacy } \\
\text { OR }(95 \% \mathrm{Cl}), p \text {-value }\end{array}$ & $\begin{array}{c}\text { Drug Burden Index (DBI) }>0 \\
\text { OR }(95 \% \mathrm{Cl}), p \text {-value }\end{array}$ \\
\hline \multicolumn{3}{|l|}{ Unadjusted Models } \\
\hline Frailty (GFI >4) & $4.62(1.68-12.70), 0.001$ & $1.56(0.74-3.30), 0.704$ \\
\hline Poor QOL (OPQOL <110) & 1.23 (0.59-2.53), 0.571 & 0.81 (0.39-1.67), 0.571 \\
\hline Depression (HADS >7) & $1.28(0.45-3.62), 0.643$ & $0.78(0.28-2.22), 0.643$ \\
\hline Anxiety (HADS >7) & $1.16(0.44-3.05), 0.763$ & $0.57(0.23-1.42), 0.227$ \\
\hline KATZ ADL (Dependence $=0$ ) & 0.64 (0.28-1.49), 0.303 & $1.29(0.55-3.03), 0.558$ \\
\hline \multicolumn{3}{|l|}{ Adjusted Models ${ }^{a}$} \\
\hline Frail (GFI >4) & $6.07(1.71-21.56), 0.005$ & $1.09(0.39-3.04), 0.862$ \\
\hline Poor QOL (OPQOL <110) & 0.64 (0.26-1.59), 0.332 & 1.35 (0.49-3.68), 0.560 \\
\hline Depression (HADS >7) & $1.01(0.32-3.20), 0.990$ & $0.39(0.11-1.41), 0.152$ \\
\hline Anxiety (HADS >7) & $1.12(0.29-4.30), 0.867$ & $0.51(0.11-2.37), 0.394$ \\
\hline KATZ ADL (Dependence $=0$ ) & 1.37 (0.47-3.98), 0.567 & $1.60(0.43-6.01), 0.487$ \\
\hline
\end{tabular}

$\mathrm{OR}=$ Odds Ratio; $\mathrm{Cl}=$ Confidence Interval; $\mathrm{QOL}=$ Quality of Life;

Referents were non-frail, Good QOL, no depression, no anxiety, KATZ independence, no polypharmacy, DBI = 0

aOdds ratio adjusted for age, sex, marital status, co-morbid conditions, HADS-depression, HADS-anxiety, OPQOL, GFI, KATZ ADL, polypharmacy, DBI. Classification method used was logistic 


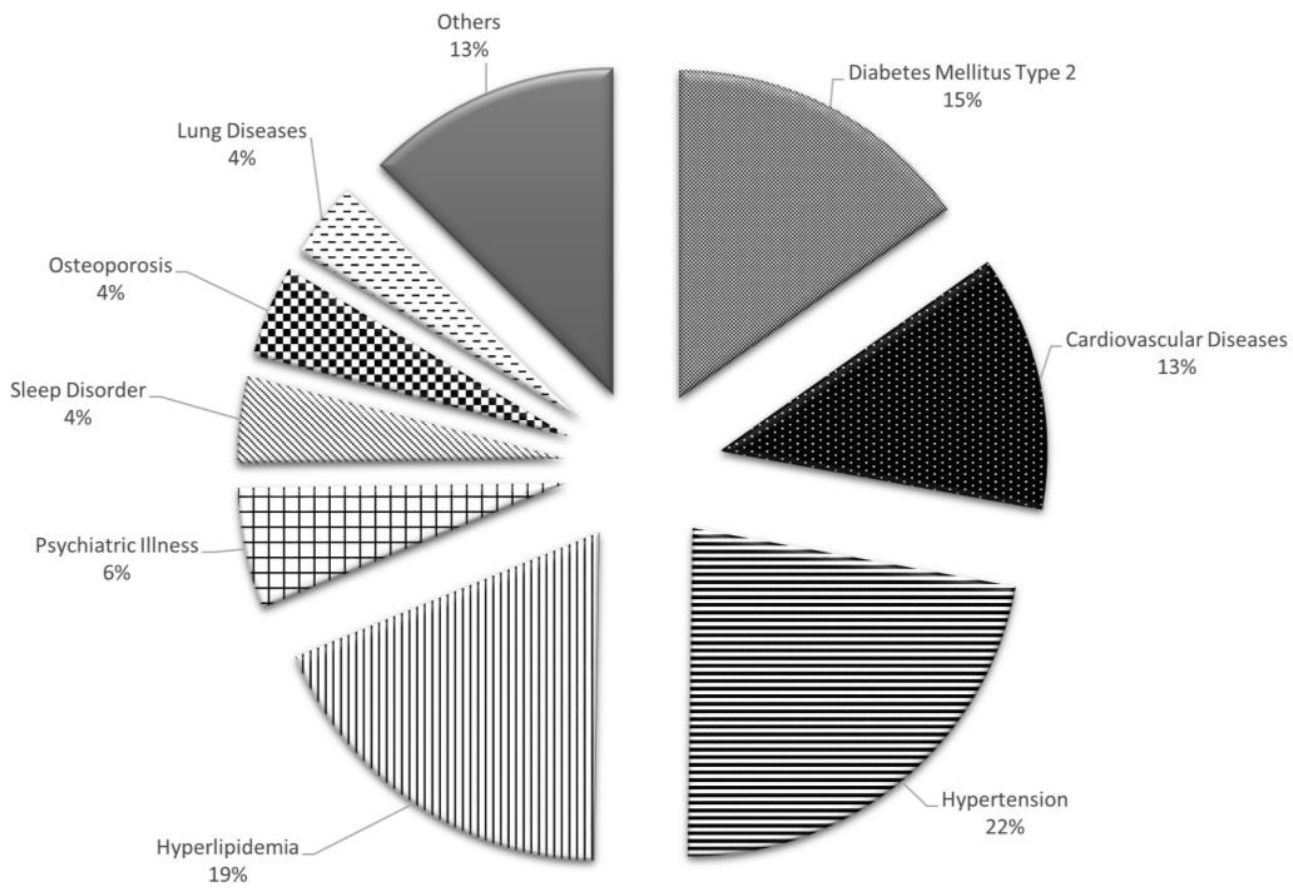

Figure 1: Pre-existing medication conditions at the time of data collection 